\title{
Exploitation of walleye in a Great Plains reservoir: harvest patterns and management scenarios
}

\author{
M. C. QUIST \\ J. L. STEPHEN \\ Kansas Department of Wildlife and Parks, Emporia, KS, USA
}

Department of Natural Resource Ecology and Management, Iowa State University, Ames, IA, USA

\author{
S. T. LYNOTT \\ Kansas Department of Wildlife and Parks, Independence, KS, USA
}

J. M. GOECKLER

Kansas Department of Wildlife and Parks, Emporia, KS, USA

\author{
R. D. SCHULTZ \\ Iowa Department of Natural Resources, Chariton, IA, USA
}

\begin{abstract}
This study assessed exploitation and evaluated management options for walleye, Sander vitreus (Mitchill), in Glen Elder Reservoir, Kansas. A total of 2429 walleye varying from 240 to $687 \mathrm{~mm}$ was tagged with Carlin dangler tags during 2000-2003. After correcting for tag loss and non-reporting, exploitation of walleye was estimated as $68.3 \%$. More than $85 \%$ of the tagged walleye were harvested during April to June and $75 \%$ were harvested within 6 months after tagging. A Beverton-Holt yield-per-recruit model was used to evaluate six minimum length limits varying from 250 to $610 \mathrm{~mm}$. Given current exploitation rates, population demographics and harvest regulations (381-mm minimum length limit), the walleye population is probably experiencing recruitment overfishing. Model results suggested that a $610-\mathrm{mm}$ minimum length limit would be required to prevent growth overfishing and a 533-mm or longer minimum length limit would prevent recruitment overfishing.
\end{abstract}

KEYWORDS: growth overfishing, partial-year minimum length limit, recruitment overfishing.

\section{Introduction}

Walleye, Sander vitreus (Mitchill), is one of the more important fishes in North America due to its ecological role in aquatic communities and its value in recreational, commercial and tribal fisheries (Colby et al. 1979; Baccante \& Colby 1996; Carlander 1997). The native distribution of walleye is limited to natural lakes and rivers in Canada and the northern USA (Colby et al. 1979; Carlander 1997; Craig 2000). Consequently, this region supports the majority of commercial and tribal fisheries. By contrast, recreational walleye fisheries are important across North America, largely due to their widespread occurrence resulting from extensive construction of reservoirs and subsequent walleye introduction programmes (Colby et al.

Correspondence: Michael C. Quist, Department of Natural Resource Ecology and Management, 339 Science II, Iowa State University, Ames, IA, 50011, USA (e-mail: mcquist@iastate.edu) 
1979). Introductions of walleye to systems west of their native distribution have shown limited success, but introductions to systems (e.g. reservoirs) in the Great Plains have been very successful and now support important recreational fisheries (e.g. Porath \& Peters 1997).

Kansas is located in the Great Plains region of the USA. Although walleye may have been present in the Missouri River along the Kansas-Missouri border prior to European settlement, walleye is considered a non-native species in the state (Cross \& Collins 1995). As a result of reservoir construction in the 1960s and 1970s and an intensive stocking programme by the Kansas Department of Wildlife and Parks (KDWP), walleye quickly established throughout Kansas and has remained one of the state's more popular sport fish (Burlingame 1998; KDWP 2008). Due to its ecological and recreational importance, a number of studies have been conducted to understand its ecology and management. Walleye in Kansas reservoirs experience relatively fast growth (Quist et al. 2002, 2003a) and variable recruitment (Willis \& Stephen 1987; Quist et al. 2003b). Quist et al. (2004a) found age structure of Kansas walleye populations was dominated by young fish with few fish older than age 6 , and annual mortality was high (41-60\%). Length structure of walleye populations across Kansas was almost always truncated at a length at which fish were first available for harvest, suggesting that harvest may play an important role in the dynamics of walleye populations. In addition to describing age structure and mortality, these assessments also calculated mortality caps (Quist et al. 2004b). Mortality caps indicate a threshold level of annual mortality that provides managers with a warning of potential problems when annual mortality exceeds the mortality cap (Miranda 2002). Walleye populations in Kansas reservoirs managed with a 457$\mathrm{mm}$ minimum length limit had annual mortality rates approaching, but not exceeding the caps (Quist et al. 2004b). By contrast, populations managed with a 381$\mathrm{mm}$ minimum length limit exceeded the caps, raising concerns of overexploitation. Whether or not Kansas walleye populations are being overfished has not been verified, but significant declines in walleye recruitment parallel increased fishing effort [Burlingame 1998; Quist et al. 2003b; KDWP (Kansas Department of Wildlife and Parks) 2008]. To compensate for declining natural recruitment, many Kansas walleye populations have increasingly relied on supplemental stocking to maintain adult densities and provide a fishery (Quist et al. 2004b).

Preventing overfishing is a common management goal in both recreational and commercial fisheries.
Although growth overfishing is often a concern to fishery scientists, recruitment overfishing in recreational fisheries has received much less attention. Rather, most studies investigating recruitment overfishing have focused on commercially exploited fishes in marine environments (Gulland 1983; Goodyear 1993), despite the negative effects recruitment overfishing might have on recreational fisheries that experience high levels of exploitation (Post et al. 2002; Cooke \& Cowx 2006).

Walleye represents an important recreational resource in the Great Plains and fishery managers are concerned that many populations may be overfished. As such, the objectives of this research were to understand recreational exploitation and to evaluate the effects of different minimum length limits on walleye population structure in a Great Plains reservoir. To accomplish this, exploitation was estimated and then combined with walleye population metrics to evaluate the possibility of growth and recruitment overfishing and to provide guidance with regard to different harvest regulations.

\section{Materials and methods}

Glen Elder Reservoir is a 5093-ha impoundment in western Kansas, USA, that was completed in 1969. Although constructed primarily for flood control, the reservoir serves a number of agricultural, municipal and recreational needs. Glen Elder Reservoir is relatively shallow (mean depth $=5.8 \mathrm{~m}$ ), moderately turbid (Secchi transparency $=1.0-3.5 \mathrm{~m}$ ) and does not thermally stratify due to persistent high winds (Quist et al. 2002). Water temperatures typically exceed $24{ }^{\circ} \mathrm{C}$ for several weeks and often reach $28^{\circ} \mathrm{C}$ in summer. Gizzard shad, Dorosoma cepedianum (Lesueur), is abundant and the dominant prey species (Quist et al. 2002). Important sport fishes include channel catfish, Ictalurus punctatus (Rafinesque), white bass, Morone chrysops (Rafinesque), and walleye. Although most Kansas reservoirs support a walleye fishery, Glen Elder Reservoir has historically been considered one of the state's premier walleye fisheries. This reputation is based on the high numbers of large walleye that were harvested in the 1970-1990s (J.L. Stephen, unpublished data). However, abundance, recruitment and size structure of walleye in Glen Elder Reservoir (and many other Kansas populations) have declined during the last 10 years suggesting potential growth and recruitment overfishing (Quist et al. 2003b). The walleye fishery is managed with a 381$\mathrm{mm}$ minimum length limit and a 5 -fish daily bag limit.

Fish were collected using night electric fishing during autumn (October to November) and spring (March to 
April) in each of three tagging seasons: 2000-2001 (i.e. October to November 2000, March to April 2001), 2001-2002 and 2002-2003. Collected fish were measured for total length (nearest $\mathrm{mm}$ ) and weighed (g).

Fish were tagged with Carlin dangler tags. Tags had a $0.25-\mathrm{mm}$ diameter stainless steel wire bridle with a $4.7 \times 15.9-\mathrm{mm}$ long oval plastic tag (Floy Tag and Mfg., Inc., Seattle, Washington). The tagging process began by first removing a scale just posterior and ventral to the soft dorsal fin. A 14-gauge hypodermic needle was then passed through the body. One wire was passed through the needle, the needle was removed, and the two ends of wire were twisted. The wire was tightened to a point where approximately $13 \mathrm{~mm}$ of space remained between the wire and the fish's body to allow for growth. The twisted portion of the wire was trimmed and then positioned inside the fish's body to ensure that the plastic tag was aligned with the dorsal midline of the fish. A unique identification number and '\$ REWARD \$' was printed on one side of the tag. The opposite side of the tag was printed with 'KDWP, Box 1525, Emporia, KS 66801'. Media (i.e. radio, newspaper) and signage at local businesses, park entrances and boat ramps informed anglers of the study. Rewards of US $\$ 5, \$ 20$ or $\$ 100$ were randomly assigned to each tag. Anglers were unaware of the reward amount until they returned the tag and received the reward in the mail. Anglers reporting a tagged fish were asked to provide information on the capture date and location and whether the fish was harvested.

Tag loss was evaluated by tagging 100 walleye and holding them for 6 months at Milford Fish Hatchery, Junction City, KS. Tag loss was $9 \%$ and all fish that lost their tag retained the wire bridle. Tag nonreporting was evaluated using a postcard survey similar to Schultz and Robinson (2002), in which pre-addressed postcards $(n=100)$ were placed on the windshield of vehicles parked at boat ramps. Similar to tagged fish, anglers were informed that if they completed the postcard, they would receive a cash reward of US $\$ 5, \$ 20$ or $\$ 100$. Only 36 postcards were returned, yielding a non-reporting rate of $64 \%$.

Temporal patterns in harvest were evaluated by summarising the number of fish harvested in each month and the time at large of tagged fish. Anglers did not report the length of fish at harvest, so, a sizespecific growth model (Putnam et al. 1995) was developed to estimate the length of fish at harvest using age and growth data from walleye in Glen Elder Reservoir (Quist et al. 2003a). The distribution of estimated lengths at harvest was compared with the lengths of fish sampled as part of KDWP's annual monitoring efforts. Standard population sampling efforts included the use of gillnets and provided a measure of population size structure (Willis \& Stephen 1987; Quist et al. 2003a,b, 2004b). A Kolmogorov-Smirnov test was used to evaluate whether the estimated lengths of harvested fish differed from those sampled during standard population monitoring efforts (Sokal \& Rohlf 1995). Length-frequency comparisons included only fish greater than $381 \mathrm{~mm}$ (the minimum length limit). Exploitation was estimated as the number of fish harvested (corrected for tag non-reporting) divided by the number of fish tagged (corrected for tag loss). Exploitation estimated using the non-reporting rate of $64 \%$ from the postcard assessment resulted in an exploitation rate that exceeded $100 \%$. Therefore, a non-reporting rate of $25 \%$ was used to estimate exploitation. Although this rate is lower than that from the postcard survey, it is consistent with other non-reporting rates reported for Kansas anglers (Schultz \& Robinson 2002) and results in a conservative (low) estimate of exploitation relative to one using a non-reporting rate of $64 \%$.

The effects of harvest on walleye populations and different management strategies (i.e. length limits) were simulated using a Beverton-Holt yield-per-recruit model. Reproductive parameters, growth rate, maximum age, and the length-weight relationship specified in the model were based on previous research on Glen Elder Reservoir (Quist et al. 2002, 2003a,b, 2004a). With regard to reproductive characteristics, $50 \%$ of the age- 2 and all of the age- 3 and older female fish were mature (Quist et al. 2002). A 50:50 sex ratio was used in all simulations. Growth was described using the von Bertalanffy growth model presented in Quist et al. (2003a): $L_{t}=702\left(1-\mathrm{e}^{-0.373(t+0.101)}\right)$, where $L_{t}$ is the length at age $t$. Maximum age was input as 8 years. The length-weight relationship, $\log _{10}$ (weight $)=$ $-5.700+3.272\left[\log _{10}(\right.$ length $\left.)\right]$, was developed using fish sampled from Glen Elder Reservoir during 2000$2006\left(n=8783, r^{2}=0.99, P=0.001\right)$. Conditional natural mortality $(\mathrm{cm}$; mortality that occurs in absence of fishing mortality) was modelled at $0,0.05$ and 0.10 . These rates reflect the best estimates of $\mathrm{cm}$ for walleye in Glen Elder Reservoir based on the body of previous research conducted on the walleye population in the reservoir. Conditional fishing mortality ( $c f$; mortality due to fishing in absence of natural mortality) was modelled at varying levels to obtain exploitation rates from 0 to $90 \%$. Simulations were conducted using minimum length limits of $250,381,457,533,559$ and $610 \mathrm{~mm}$. The $250-\mathrm{mm}$ minimum length limit represented a scenario of unregulated harvest. The $381-\mathrm{mm}$ minimum length limit was the current length limit for Glen Elder Reservoir. A 457-mm minimum length 
limit was also investigated because it is a common minimum length limit for managing walleye populations in Kansas reservoirs. The $533-\mathrm{mm}$ minimum length limit represents the harvest regulation for Cheney Reservoir, another popular walleye fishery in Kansas. This minimum length limit was implemented on the walleye fishery in Cheney Reservoir in 2003 with a goal of increasing the size structure of walleye and reducing the density of introduced white perch, Morone americana (Gmelin). The 559-mm and 610$\mathrm{mm}$ length limits were investigated because they have been extensively discussed by fishery biologists in the Great Plains.

Yield was plotted against exploitation to evaluate the possibility of growth overfishing (Slipke \& Maceina 2001). The potential for recruitment overfishing was also examined. Recruitment overfishing is traditionally examined by assessing the reproductive potential of an exploited population relative to that of an unexploited population (Goodyear 1993; Mace \& Sissenwine 1993). Spawning potential ratio $(S P R)$ represents the proportion of lifetime egg production of a cohort $(P)$ in an exploited population compared with that of an unexploited population and is calculated as:

$$
S P R=\left[100 \times\left(P_{\text {exploited }} / P_{\text {unexploited }}\right)\right] .
$$

Overharvest was interpreted to occur at an $S P R$ of $20 \%$ (Goodyear 1993). Fecundity data were not available for Kansas walleye populations, so a length-fecundity relationship was obtained from Carlander (1997): $\log _{10}($ fecundity $)=-5.293+3.829$ $\log _{10}$ (length). All population simulations were conducted in Fisheries Analysis and Simulation Tools (FAST; Slipke \& Maceina 2001) with an initial population of 1000 recruits. All other statistical analyses were conducted using SAS (SAS 2006).

\section{Results}

A total of 2429 walleye varying in length from 240 to $687 \mathrm{~mm}$ was tagged during the three tagging seasons (Table 1). The total number of tags returned from harvested fish was 1132 (46.6\% of tagged fish). With a

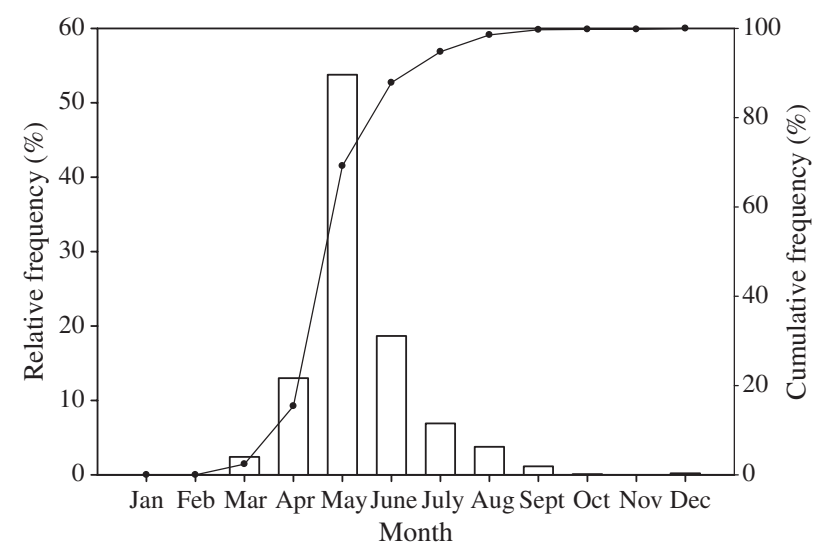

Figure 1. Harvest of tagged walleye from Glen Elder Reservoir, Kansas, 2000-2006. Open bars represent the relative frequency, and the line represents cumulative relative frequency of walleye harvest.

non-reporting rate of $25 \%$ and tag loss of $9 \%$, the annual exploitation estimate was $68.3 \%$.

Approximately $85 \%$ of the tagged fish were harvested during April to June and 54\% of all tagged fish were harvested in May (Fig. 1). Few fish were harvested in the summer and autumn, and no tagged fish were reportedly harvested in January, February or November. Nearly all of the fish were harvested shortly after tagging. Specifically, $60.6 \%$ of the fish were harvested within 2 months after tagging, $75.7 \%$ were harvested within 6 months, and $82.5 \%$ were harvested within 1 year (Fig. 2). Approximately 95\% of the fish were harvested within 16 months of tagging. The estimated length distribution of harvested fish was similar to that observed during standardised sampling ( $D=0.17, P=0.37$; Fig. 3$)$, indicating that anglers were not selectively harvesting small or large walleye.

Results of the Beverton-Holt models demonstrated how yield would vary with different harvest regulations and mortality rates (Fig. 4). Although predicted yield varied among length limits and levels of $\mathrm{cm}$, several patterns were apparent. Yield declined with increasing levels of natural mortality and was similar

Table 1. Tagging season, minimum, maximum, and mean length $(\mathrm{mm})$ at tagging and number of walleye tagged and harvested in Glen Elder Reservoir, Kansas

\begin{tabular}{lccccc}
\hline $\begin{array}{l}\text { Tagging } \\
\text { season }\end{array}$ & $\begin{array}{c}\text { Number } \\
\text { tagged }\end{array}$ & $\begin{array}{c}\text { Number } \\
\text { harvested }\end{array}$ & $\begin{array}{c}\text { Minimum } \\
\text { length }\end{array}$ & $\begin{array}{c}\text { Maximum } \\
\text { length }\end{array}$ & $\begin{array}{c}\text { Mean length } \\
(\text { SE) }\end{array}$ \\
\hline $2000-2001$ & 991 & 490 & 240 & 681 & $476.0(58.4)$ \\
$2001-2002$ & 846 & 303 & 257 & 668 & $456.0(54.6)$ \\
$2002-2003$ & 592 & 339 & 340 & 687 & $451.2(61.0)$ \\
\hline
\end{tabular}




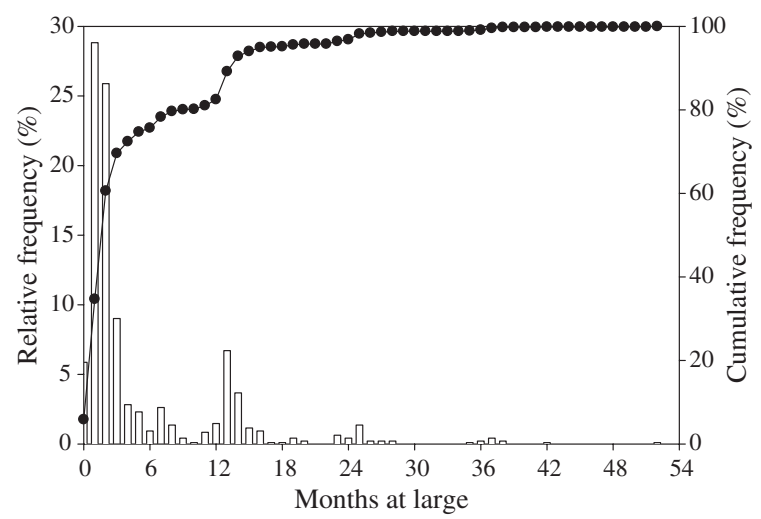

Figure 2. Months at large (i.e. number of months between tagging and harvest) of walleye harvested from Glen Elder Reservoir, Kansas, 20002006. Open bars represent the relative frequency, and the line represents cumulative relative frequency of walleye harvest.

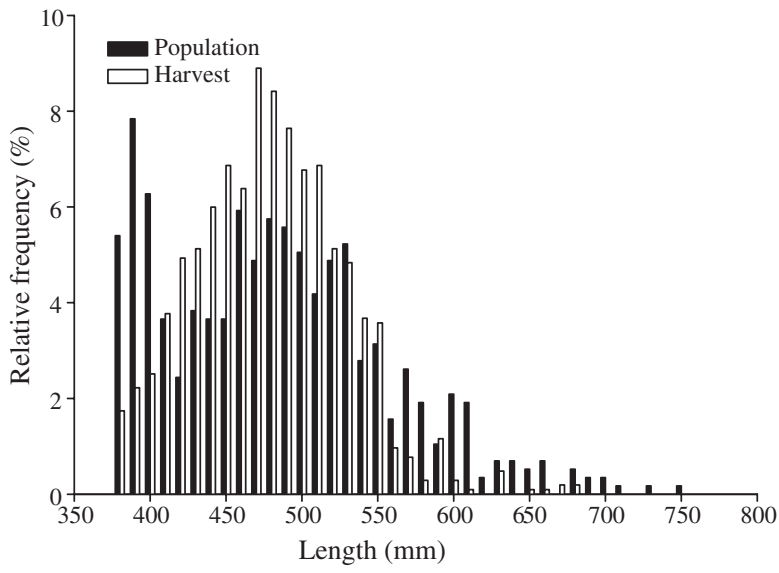

Figure 3. Length-frequency distributions for walleye sampled during routine population assessments (solid bars) and angler-harvested tagged walleye (open bars) from Glen Elder Reservoir, Kansas, 2000-2006.

among length limits at low $(\leq 20 \%)$ exploitation. Without any natural mortality $(\mathrm{cm}=0)$, yield was generally highest with the $533-\mathrm{mm}$ minimum length limit and nearly double that with no length limit (i.e. $250 \mathrm{~mm}$ ) or with a 381-mm minimum length limit, especially when exploitation was greater than $40 \%$. Both the 559- and 610-mm minimum length limits prevented growth overfishing (i.e. reduced yield with increased exploitation) at exploitation up to $60 \%$, but only the $610-\mathrm{mm}$ minimum length limit prevented growth overfishing at all levels of exploitation when $\mathrm{cm}$ was 0 . When $\mathrm{cm}$ was 0.05 , yield was consistently higher with the 559- and 610-mm minimum length limits. Similarly, the most restrictive harvest regulations tended to have the higher yields when $\mathrm{cm}$ was 0.10 . When $\mathrm{cm}$ was 0.05 or 0.10 , the 533-, 559- and $610-\mathrm{mm}$
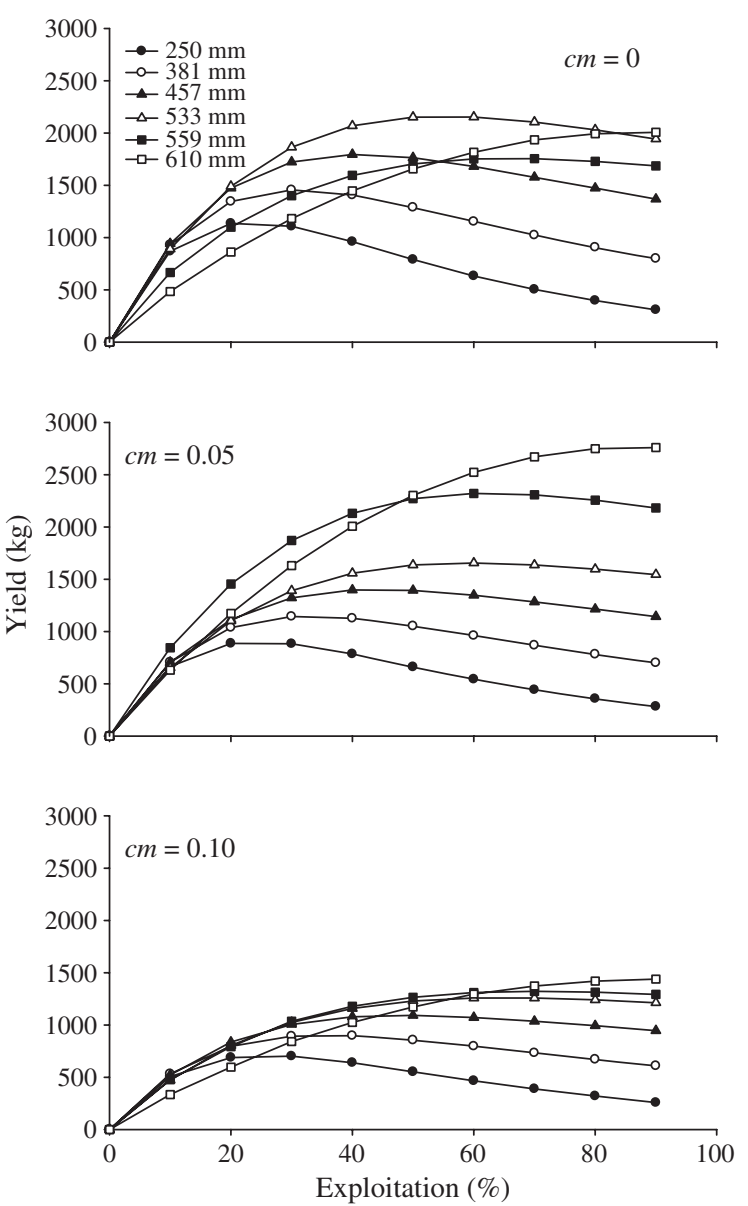

Figure 4. Simulated yields for walleye in Glen Elder Reservoir, Kansas, with three rates of conditional natural mortality $(\mathrm{cm})$ and six minimum length limits.

minimum length limits would probably prevent growth overfishing until exploitation reached $60-70 \%$. Only the $610-\mathrm{mm}$ minimum length limit would protect walleye from growth overfishing at all levels of exploitation and $\mathrm{cm} \leq 0.10$.

Spawning potential ratios were similar among levels of $\mathrm{cm}$ and decreased with increasing exploitation and less restrictive minimum length limits (Fig. 5). The two least restrictive length limits (i.e. $250 \mathrm{~mm}$ and $381 \mathrm{~mm}$ ) resulted in recruitment overfishing (i.e. $S P R \leq 20 \%$ ) at $40-50 \%$ exploitation. The $533-\mathrm{mm}$ and longer minimum length limits prevented $S P R$ from declining to $20 \%$ at all levels of exploitation.

\section{Discussion}

Exploitation of walleye in Glen Elder Reservoir was high. Baccante and Colby (1996) summarised information on density, harvest, and reproductive 

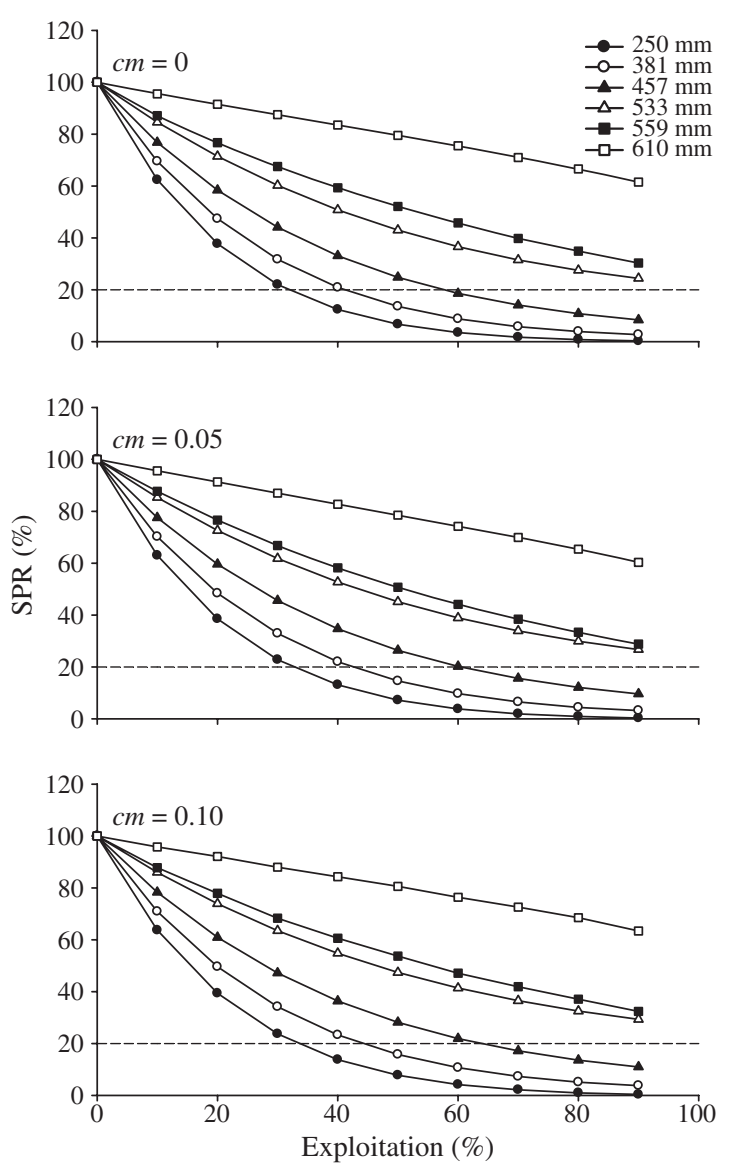

Figure 5. Simulated spawning potential ratio $(S P R)$ for walleye in Glen Elder Reservoir, Kansas, with different rates of conditional natural mortality $(\mathrm{cm})$ and minimum length limits. The horizontal dashed line represents the recruitment overfishing threshold of $20 \%$.

characteristics of walleye populations across North America. Exploitation estimates for 46 walleye populations varied from $3.0 \%$ to $55.6 \%$ and averaged $19.6 \%$ $(\mathrm{SE}=1.6)$; four populations had exploitation estimates greater than $30 \%$ and two populations had rates greater than $50 \%$. Exploitation of walleye in Glen Elder Reservoir was estimated as $68.3 \%$. Not only is this estimate high, but the estimate could be considered low in that the non-reporting rate used to correct the number of tag returns (i.e. 25\%) was considerably lower than the $64 \%$ rate measured with the postcard survey. The reason for low postcard returns is unknown, but may be because of poor publicity associated with the postcard survey. Regardless, an absolute minimum exploitation estimate based solely on the proportion of tags returned and not adjusted for non-reporting or tag loss was $46.6 \%$, suggesting that exploitation of walleye in Glen Elder Reservoir was high compared with other walleye fisheries.
Responses of fish populations to exploitation include high variability in recruitment, early age at reproduction and fast growth (Regier \& Loftus 1972). Such responses are particularly evident in percid populations (Spangler et al. 1977; Reid \& Momot 1985). For instance, Schupp and Macins (1977) described an increase in recruitment variation as exploitation of walleye increased in Lake of the Woods, Minnesota. Similarly, Spangler et al. (1977) provided examples of how growth rates increased and age at maturity decreased in walleye from Lake Erie in response to increased harvest. Walleye in Kansas are generally $20-30 \%$ longer at age than walleye in other regions of North America (Quist et al. 2003a). Although warm temperatures and long growing seasons probably contribute to fast growth of walleye in Kansas, exploitation may also play an important role with regard to growth. For most fish, age at maturity typically declines as growth rate increases. All male and approximately half of the female walleye in Kansas reservoirs mature at age 2, compared with slower growing fish in other systems that may not mature until age 3 or older (males) or age 5 or older (females; Colby et al. 1979; Carlander 1997). Froese (2004) presented the seemingly obvious tenets associated with preventing overfishing as letting fish spawn, letting fish grow, and allowing large females to survive and reproduce. In Glen Elder Reservoir, walleye are not able to grow and spawn because they are harvested before or near maturity. Specifically, some fish are available for harvest (i.e. $381 \mathrm{~mm}$ ) at age 1 and nearly all age-2 fish have recruited to the fishery. Age-1 walleye are not mature; and, although males are mature at age 2, only about half of the age- 2 female walleye are sexually mature. Thus, recruitment overfishing is likely occurring in this fishery.

Reducing or eliminating the negative effects of harvest in recreational fisheries is often accomplished using restrictive length limits. The objectives of length limits vary, but are often implemented to maximise yield, increase catch of large fish or protect spawning fish (Brousseau \& Armstrong 1987; Noble \& Jones 1999). Minimum length limits are particularly common in freshwater fisheries and are most likely to be effective when (1) natural recruitment is limited, (2) growth is fast, (3) natural mortality is low and (4) exploitation is high (Serns 1978; Brousseau \& Armstrong 1987). The effectiveness of minimum length limits on walleye fisheries varies with some studies reporting negative or no effects and others showing positive effects from length limits. For instance, Serns (1978) found that a 381-mm minimum length limit on walleye in Big Crooked Lake, Wisconsin did not 
produce the desired response of higher densities of walleye larger than the minimum length limit. The number of walleye in the population less than $381 \mathrm{~mm}$ increased, but those greater than $381 \mathrm{~mm}$ decreased by nearly $70 \%$. Serns (1978) suggested that the reason for poor results of the length limit was that successive strong year classes reduced growth rates of small fish and resulted in stockpiling of fish less than the minimum length limit. Isermann (2007) evaluated the benefits of 356- and 381-mm minimum length limits on walleye populations in Minnesota lakes and found little or no measureable influence on walleye abundance, size structure or age structure. Fayram et al. (2001) evaluated a 381-mm minimum length limit on 19 lakes in northern Wisconsin. The minimum length limit had a negative effect on angler harvest and no influence on angler catch rates, walleye abundance or size structure. However, the authors argued that low exploitation across the study lakes $($ mean $=12.8 \%$ ) probably accounted for the overall lack of measurable effects. In contrast to these studies, abundance, mean length, mean weight and angler catch and yield of walleye increased after implementation of high minimum length limits in walleye fisheries in Missouri (Goddard \& Redmond 1978), Texas (Munger \& Kraai 1997) and Wisconsin (Serns 1981).

The current $381-\mathrm{mm}$ minimum length limit is inadequate to protect against overfishing in Glen Elder Reservoir. Population models suggest a higher minimum length limit would be desirable for walleye in Glen Elder Reservoir given their fast growth, low natural recruitment, and high exploitation. Growth overfishing would likely occur for all minimum length limits less than $610 \mathrm{~mm}$ and recruitment overfishing would probably occur for all length limits less than $533 \mathrm{~mm}$. Although this study focused on one population, the results probably apply to other walleye populations. Specifically, walleye populations throughout Kansas have nearly identical growth and annual mortality rates (Quist et al. 2003a, 2004a); and, although age structure differs among populations, the differences can be explained by regulations used to manage the fishery (Quist et al. 2004a). Specifically, length structure of populations managed with a minimum length limit is typically truncated at or near the minimum length limit. Unfortunately, long-term evaluations on the efficacy of minimum length limits are rare; therefore, it is difficult to predict the response of populations to regulation changes. However, a recent change in the management of Cheney Reservoir provides insight on how walleye might respond to more restrictive minimum length limits. Prior to 2003, walleye in Cheney Reservoir experienced fast growth
(Quist et al. 2003a) and high annual mortality (46.1\%; Quist et al. 2004a). Similar to most walleye populations in Kansas, recruitment of walleye has also declined in Cheney Reservoir since the mid 1980s (Quist 2007). In 2003, the existing 457-mm minimum length limit was changed to a $533-\mathrm{mm}$ minimum length limit to increase the size structure of walleye and predation on white perch. Following the regulation change, walleye size structure and recruitment increased (Fig. 6), and catch rate of age-0 walleye (an index of recruitment in Kansas; Quist et al. 2004a) increased from a mean 1.1 fish per gillnet night $(\mathrm{SE}=1.0)$ during 1998-2002 to 7.6 fish per gillnet night (6.0) during 2003-2008. A variety of factors may be responsible for increased recruitment of walleye in
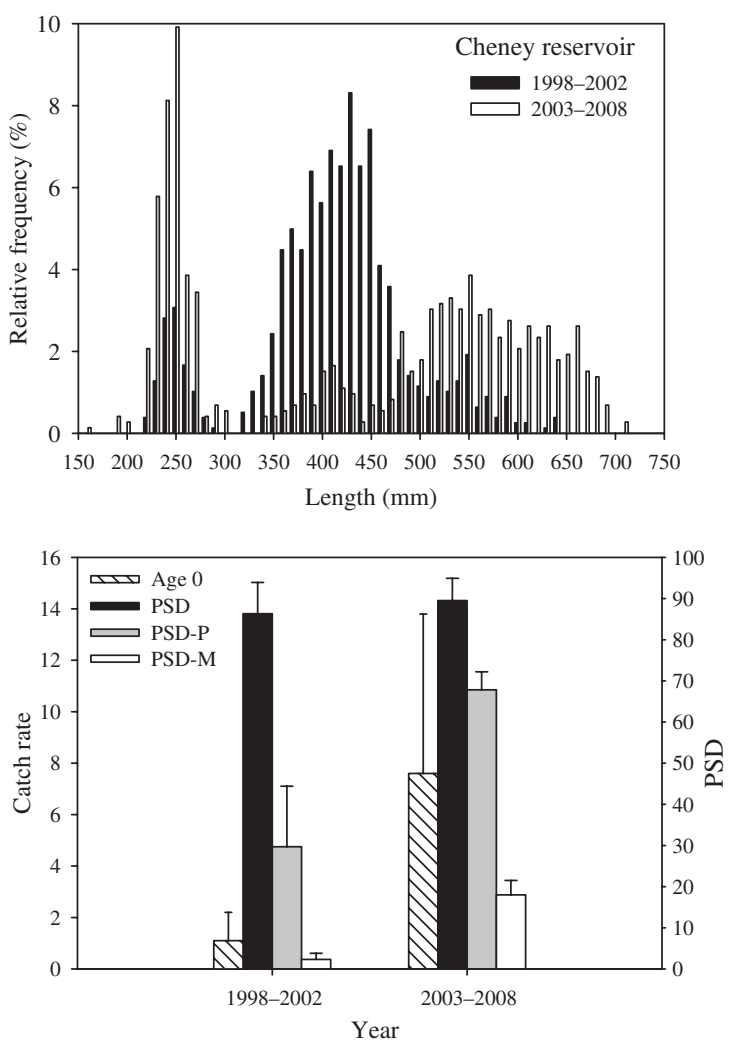

Figure 6. Length-frequency distribution (upper panel) of the walleye population in Cheney Reservoir, Kansas, before (solid bars; 1998-2002) and after (open bars; 2002-2008) the minimum length limit was changed from a $457-\mathrm{mm}$ minimum to a $533-\mathrm{mm}$ minimum length limit. The lower panel provides estimates of the catch rate (number per gillnet night) of age- 0 walleye, proportional size distribution (PSD = $100 \times$ number of fish $\geq 380 \mathrm{~mm} /$ number of fish $\geq 250 \mathrm{~mm}$ ), PSD of preferred-length fish (PSD-P $=100 \times$ number of fish $\geq 510 \mathrm{~mm} /$ number of fish $\geq 250 \mathrm{~mm}$ ), and PSD of memorable-length fish (PSD$\mathrm{M}=100 \times$ number of fish $\geq 630 \mathrm{~mm} /$ number of fish $\geq 250 \mathrm{~mm}$ ). Error bars represent one standard error. Data were provided by J. Stein and G. Schneider, Kansas Department of Wildlife and Parks. 
Cheney Reservoir, but the population demographics of walleye in Cheney Reservoir (and other reservoir systems in Kansas) are virtually identical to those in Glen Elder Reservoir (e.g. Quist et al. 2003a, 2004b) and suggest that the modelling results presented in this study are widely applicable. Therefore, an increase in recruitment in Cheney Reservoir may be a response to reduced harvest.

As with any aspect of fisheries management, lack of public support will hinder efforts to make changes in harvest regulations (Noble \& Jones 1999). The results of this study suggest a $533-\mathrm{mm}$ or longer minimum length limit is needed to protect against recruitment overfishing, and a $610-\mathrm{mm}$ length limit may be needed to prevent growth overfishing. A $610-\mathrm{mm}$ minimum length limit would reduce yield at present levels of exploitation and probably not receive widespread support from the public, but a 533-mm minimum length limit may be acceptable to most anglers. Although there was initial opposition to the change in regulations to a 533-mm minimum length limit at Cheney Reservoir, most anglers are now satisfied with the walleye fishery (J. Stein, KDWP, personal communication). Despite the angler acceptance at Cheney Reservoir, recent efforts to implement more restrictive regulations in other systems have been unsuccessful because many anglers were concerned about their ability to harvest small- to intermediate-length walleye. Many biologists are also concerned about delayed or release mortality of fish (e.g. hooking and handling mortality) in summer. Reeves and Bruesewitz (2007) found that post-release mortality of angler-caught walleye increased significantly when water temperatures exceeded $20^{\circ} \mathrm{C}$. Boland (1991) found that delayed mortality of angler-caught walleye in Iowa dramatically increased after water temperatures exceeded $21{ }^{\circ} \mathrm{C}$. Similarly, Fielder and Johnson (1994) reviewed several studies focusing on mortality of angler-caught walleye and found that mortality increased (often more than $75 \%$ mortality) when water temperatures were greater than $20^{\circ} \mathrm{C}$. Mortality of walleye caught and released in Kansas is unknown, but it may be high during summer when water temperatures regularly exceed $20^{\circ} \mathrm{C}$ and often approach $30^{\circ} \mathrm{C}$ (Quist et al. 2002). As such, concern over release mortality with a higher minimum length limit is warranted in Kansas and other walleye fisheries.

One option for reducing recruitment overfishing and addressing the concerns of anglers and biologists is the use of a partial-year minimum length limit. An example is provided by Stone and Lott (2002), where a partial-year minimum length limit was implemented in Lake Francis Case, South Dakota. All walleye caught in Lake Francis Case less than $356 \mathrm{~mm}$ had to be released during April to June and any fish could be harvested during the remainder of the year. In response to the regulation, mortality of age- 2 and age-3 walleye declined, and walleye abundance (especially fish $>356 \mathrm{~mm}$ ), size structure, mean age and angler harvest increased. Although partial-year minimum length limits have not received widespread use by managers, such regulations are well suited to fisheries that have high harvest during a short time interval and high release mortality during portions of the year.

The negative effects of overfishing have been extensively studied for commercial fisheries (Hilborn et al. 2003), but declines in fish populations attributed to recreational fishing are rarely reported, probably because they go unnoticed (McPhee et al. 2002; Post et al. 2002; Coleman et al. 2004; Cooke \& Cowx 2006). Of 27 walleye populations in Alberta for which data were available, Post et al. (2002) reported that 21 populations had collapsed due to overfishing. Prior to the study, the declines were largely unknown to managers. Although a number of factors may contribute to the lack of awareness and understanding of fish population declines (e.g. inadequate monitoring), a primary reason population declines in recreational fisheries go unnoticed is because declining fisheries are often obscured by stocking practices (Post et al. 2002; Cooke \& Cowx 2006). Such a scenario is particularly relevant to walleye fisheries that are the target of intensive stocking efforts (Ellison \& Franzin 1992). Consequently, recruitment overfishing is not a common concern and is rarely investigated for recreational fisheries, even though it may be widespread in fisheries that receive high angler effort and supplemental stockings.

Previous research has shown that walleye in Kansas exhibit fast growth, high annual mortality and declining recruitment. The current study contributes to this knowledge and demonstrates that exploitation of walleye is high $(>65 \%)$, most walleye $(85 \%)$ are harvested during April to June and current harvest regulations are not protecting the population from overfishing in Glen Elder Reservoir. A 533-mm or longer minimum length limit is necessary to protect against recruitment overfishing, but such a restrictive regulation may not be acceptable by the public and may be ineffective if release mortality is high. Innovative management strategies, such as partial-year harvest restrictions, may be necessary to sustain quality walleye fishing in Glen Elder Reservoir and other reservoirs that may be vulnerable to recruitment overfishing. 


\section{Acknowledgments}

We thank K. Austin for assistance with field sampling and the postcard survey. We also thank the staff of Milford Fish Hatchery for assisting with the tag loss portion of this study. J. Stein and G. Schneider provided information on the walleye population in Cheney Reservoir. Helpful comments on previous version of the manuscript were provided by two anonymous reviewers. Funding was provided by Kansas Department of Wildlife and Parks.

\section{References}

Baccante D.A. \& Colby P.J. (1996) Harvest, density and reproductive characteristics of North American walleye populations. Annales Zoologici Fennici 33, 601-615.

Boland T. (1991) An Evaluation of Walleye/Sauger Tournament Fishing on the Upper Mississippi River Bordering Iowa, 1988-1990. Des Moines, IA: Iowa Department of Natural Resources, 134 pp.

Brousseau C.S. \& Armstrong E.R. (1987) The role of size limits in walleye management. Fisheries 12, 2-5.

Burlingame M.N. (1998) 1995 Licensed Angler Use and Preference Survey and Attitudes Toward Angling by Secondary Education Students. MSc Thesis. Manhattan, KS: Kansas State University, 196 pp.

Carlander K.D. (1997) Handbook of Freshwater Fishery Biology: Vol. 3. Ames, IA: Iowa State University Press, 397 pp.

Colby P.J., McNicol R.E. \& Ryder R.A. (1979) Synopsis of Biological Data on the Walleye, Stizostedion v. vitreum (Mitchill 1818). Rome: FAO Fisheries Synopsis 119, 139 pp.

Coleman F.C., Figueira W.F., Ueland J.S. \& Crowder L.B. (2004) The impact of United States recreational fisheries on marine fish populations. Science 305, 1958-1960.

Cooke S.J. \& Cowx I.G. (2006) Contrasting recreational and commercial fishing: searching for common issues to promote unified conservation of fisheries resources and aquatic environments. Biological Conservation 128, 93-108.

Craig J.F. (2000) Percid Fishes: Systematics, Ecology and Exploitation. Oxford: Blackwell Scientific Publications, 400 pp.

Cross F.B. \& Collins J.T. (1995) Fishes in Kansas, 2nd edn. Lawrence, KS: University of Kansas Natural History Museum, 315 pp.

Ellison D.G. \& Franzin W.G. (1992) Overview of the symposium on walleye stocks and stocking. North American Journal of Fisheries Management 12, 271-275.

Fayram A.H., Hewett S.W., Gilbert S.J., Plaster S.D. \& Beard T.D. Jr (2001) Evaluation of a 15-inch minimum length limit for walleye angling in northern Wisconsin.
North American Journal of Fisheries Management 21, 216824.

Fielder D.G. \& Johnson B.A. (1994) Walleye mortality during live-release tournaments on Lake Oahe, South Dakota. North American Journal of Fisheries Management 14, 776-780.

Froese R. (2004) Keep it simple: three indicators to deal with overfishing. Fish and Fisheries 5, 86-91.

Goddard J.A. \& Redmond L.C. (1978) Northern pike, tiger muskellunge, and walleye populations in Stockton Lake, Missouri: a management evaluation. In: R.L. Kendall (ed.) Selected Coolwater Fishes of North America. Bethesda, MD: American Fisheries Society, pp. 313-319.

Goodyear C.P. (1993) Spawning stock biomass per recruit in fisheries management: foundation and current use. Canadian Special Publication of Fisheries and Aquatic Sciences 120, 67-81.

Gulland J.A. (1983) Fish Stock Assessment: A Manual of Basic Methods. New York, NY: Wiley and Sons, 223 pp.

Hilborn R., Branch T.A., Ernst W., Magnusson A., MinteVera C.A., Scheuerell M.D. \& Valero J.L. (2003) State of the world's fisheries. Annual Review of Environment and Resources 28, 359-399.

Isermann D.A. (2007) Evaluating walleye length limits in the face of population variability: case histories from western Minnesota. North American Journal of Fisheries Management 27, 551-568.

KDWP (Kansas Department of Wildlife and Parks). (2008) 2006 Kansas Licensed Angler Survey. Pratt, KS: Kansas Department of Wildlife and Parks, $62 \mathrm{pp}$.

Mace P.M. \& Sissenwine M.P. (1993) How much spawning per recruit is enough? Canadian Special Publication of Fisheries and Aquatic Sciences 120, 101-118.

McPhee D.P., Leadbitter D. \& Skilleter G.A. (2002) Swallowing the bait: is recreational fishing in Australia ecologically sustainable? Pacific Conservation Biology 8, 40-51.

Miranda L.E. (2002) Establishing size-based mortality caps. North American Journal of Fisheries Management 22, 433 440.

Munger C.R. \& Kraai J.E. (1997) Evaluation of length and bag limits for walleye in Meredith Reservoir, Texas. North American Journal of Fisheries Management 17, 438-445.

Noble R.L. \& Jones T.W. (1999) Managing fisheries with regulations. In: C.C. Kohler \& W.A. Hubert (eds) Inland Fisheries Management in North America, 2nd edn. Bethesda, MD: American Fisheries Society, pp. 455-477.

Porath M.T. \& Peters E.J. (1997) Walleye prey selection in Lake McConaughy, Nebraska: a comparison between stomach content analysis and feeding experiments. Journal of Freshwater Ecology 12, 511-520.

Post J.R., Sullivan M., Cox S., Lester N.P., Walters C.J., Parkinson E.A., Paul A.J., Jackson L. \& Shuter B.J. (2002) 
Canada's recreational fisheries: the invisible collapse? Fisheries 27, 6-17.

Putnam J.H., Pierce C.L. \& Day D.M. (1995) Relationships between environmental variables and size-specific growth rates of Illinois stream fishes. Transactions of the American Fisheries Society 124, 252-261.

Quist M.C. (2007) An evaluation of techniques used to index recruitment variation and year-class strength. North American Journal of Fisheries Management 27, 30-42.

Quist M.C., Guy C.S., Bernot R.J. \& Stephen J.L. (2002) Seasonal variation in condition, growth and food habits of walleye in a Great Plains reservoir and simulated effects of an altered thermal regime. Journal of Fish Biology 61, 1329-1344.

Quist M.C., Guy C.S., Schultz R.D. \& Stephen J.L. (2003a) Latitudinal comparisons of walleye growth in North America and factors influencing growth of walleye in Kansas reservoirs. North American Journal of Fisheries Management 23, 677-692.

Quist M.C., Guy C.S. \& Stephen J.L. (2003b) Recruitment dynamics of walleye (Stizostedion vitreum) in Kansas reservoirs: generalities with natural systems and effects of a centrarchid predator. Canadian Journal of Fisheries and Aquatic Sciences 60, 830-839.

Quist M.C., Stephen J.L., Guy C.S. \& Schultz R.D. (2004a) Age structure and mortality of walleye in Kansas reservoirs: use of mortality caps to establish realistic management objectives. North American Journal of Fisheries Management 24, 990-1002.

Quist M.C., Guy C.S., Bernot R.J. \& Stephen J.L. (2004b) Factors influencing growth and survival of larval walleye: implications for recruitment in a southern Great Plains reservoir. Fisheries Research 67, 215-225.

Reeves K.A. \& Bruesewitz R.E. (2007) Factors influencing the hooking mortality of walleye caught by recreational anglers on Mille Lacs, Minnesota. North American Journal of Fisheries Management 27, 443-452.

Regier H.A. \& Loftus K.H. (1972) Effects of fisheries exploitation on salmonid communities in oligotrophic lakes. Journal of the Fisheries Research Board of Canada 29, 959-968.
Reid D.M. \& Momot W.T. (1985) Evaluation of pulse fishing for the walleye, (Stizostedion vitreum vitreum), in Henderson Lake, Ontario. Journal of Fish Biology 24(Suppl A), 235-251.

SAS (Statistical Analysis System). (2006) Base SAS 9.1.3 Procedures Guide, 2nd edn. Cary, NC: SAS Institute, Inc., 1, $906 \mathrm{pp}$.

Schultz R.D. \& Robinson D.A. Jr (2002) Exploitation and mortality rates of white bass in Kansas reservoirs. North American Journal of Fisheries Management 22, 652-658.

Schupp D.H. \& Macins V. (1977) Trends in percid yields from Lake of the Woods, 1888-1973. Journal of the Fisheries Research Board of Canada 34, 1784-1791.

Serns S.L. (1978) Effects of a minimum length limit on the walleye population of a northern Wisconsin lake. In: R.L. Kendall (ed.) Selected Coolwater Fishes of North America. Bethesda, MD: American Fisheries Society, Special Publication 11, pp. 390-397.

Serns S.L. (1981) Effects of a Minimum Length Limit on the Walleye Population of Wolf Lake, Vilas County, Wisconsin. Madison, WI: Wisconsin Department of Natural Resources, $11 \mathrm{pp}$.

Slipke J.W. \& Maceina M.J. (2001) Fishery Analysis and Simulation Tools (FAST), Version 1.1. Auburn, AL: Department of Fisheries and Allied Aquacultures, Auburn University, $146 \mathrm{pp}$.

Sokal R.R. \& Rohlf F.J. (1995) Biometry, 3rd edn. New York, NY: W. H. Freeman and Company, 887 pp.

Spangler G.R.N., Payne R., Thorpe J.E., Byrne J.M., Reiger H.A. \& Christie W.J. (1977) Response of percids to exploitation. Journal of the Fisheries Research Board of Canada 34, 1983-1988.

Stone C. \& Lott J. (2002) Use of a minimum length limit to manage walleye in Lake Francis Case, South Dakota. North American Journal of Fisheries Management 22, 975984.

Willis D.W. \& Stephen J.L. (1987) Relationships between storage ratio and population density, natural recruitment, and stocking success of walleye in Kansas reservoirs. North American Journal of Fisheries Management 7, 279282. 